Research Article

\title{
Experimental Research Based on the Optical Fiber Sensing Technology for a Jacked PHC Pipe Pile Penetration Process
}

\author{
Songkui Sang $\mathbb{D}^{D}$, Yonghong Wang ${ }^{\mathbb{D}}$, Jiaxiao Ma, and Mingyi Zhang \\ School of Civil Engineering, Qingdao University of Technology, Qingdao, China \\ Correspondence should be addressed to Yonghong Wang; wangyonghong@edu.qut.cn
}

Received 23 April 2020; Revised 29 May 2020; Accepted 15 June 2020; Published 8 July 2020

Academic Editor: Yixian Wang

Copyright (c) 2020 Songkui Sang et al. This is an open access article distributed under the Creative Commons Attribution License, which permits unrestricted use, distribution, and reproduction in any medium, provided the original work is properly cited.

\begin{abstract}
The aim of this work is to explore the influence of the end resistance and shaft resistance regarding the mechanism for jacked pile penetration and the load-transfer rule during the penetration process. A full-scale field test was conducted in an actual project located in Dongying, Shandong Province, China. In this test, the axial strain experienced by two closed Prestressed High-strength Concrete (PHC) pipe piles during jacking into layered soil was monitored successfully using Fiber Bragg Grating (FBG) sensors mounted on the pile shaft. The experimental results show that FBG sensors have a good stability, strong antijamming performance, and can effectively monitor the pile stress. The variation law of the jacking force reflects the distribution of the soil layer, and the hardness of the soil layer at the pile end limits the pile force. When the pile end enters the silt layer from the clay layer, the jacking force and shaft resistance increase by 2.5 and 1.7, respectively. The shaft resistance accounted for $44.99 \%$ of the jacking force. The end resistance is affected by the mechanical properties of soil, and the end resistance of the silt layer is approximately twice that of the clay layer. The end resistance of the silt layer accounted for $59.84 \%$ of the jacking force. When the pile end enters the soft soil layer from the hard soil layer, the impact of the pile driving speed and the tangential force on the surface of the pile body must both be considered. During the pile penetration process, as the penetration depth increases, the radial stress on the pile side at a given depth is gradually released, while the shaft resistance at the pile side degrades significantly.
\end{abstract}

\section{Introduction}

A Prestressed High-strength Concrete (PHC) pipe pile is a hollow cylindrical precast concrete member produced by pretension prestressing, centrifugal techniques, and high temperature curing [1-4]. PHC pipe piles are widely used in foundation works in civil, municipal, and other projects in China due to the advantages of a high bearing capacity, high construction efficiency, and reliable quality [5-8]. The hydraulic jacking method is a common technique for pile penetration that has several advantages such as being vibration-free and noise-free during construction [9-12]. This method is generally used to press a PHC pipe pile into the site soil.

In the recent years, fiber optic sensing technologies have developed rapidly, and various sensors based on the fiber optic sensing technology are widely used in engineering monitoring [13-19]. Compared with traditional sensors such as strain gauges, fiber optic sensing technology has the advantages of a high test accuracy, strong anti-interference ability, and wide monitoring rang [20-24]. Scholars around the world have conducted thorough research on the strain distribution and penetration characteristics of piles using fiber optic sensors. Klar et al. [25] adhered optical fibers to steel reinforcing bars of a pile to monitor their performance based on the Brillouin optical time domain reflectometer (BOTDR) technology. Lu et al. [26] measured the strain of precast concrete piles using optical fibers based on the BOTDR technology. Ding et al. [27] monitored the strain of an $\mathrm{H}$-pile in SWM based on the Brillouin optical time domain analysis (BOTDA) technology. Guo et al. [28] adopted Brillouin optical frequency domain analysis (BOFDA) technology with a steel stress meter to monitor the strain, stress, and axial force of a bridge pile foundation.

To further improve the accuracy and resolution of the tests, Fiber Bragg Grating (FBG) sensors have been used to 
monitor the stress and strain of pile foundations. Lee et al. [29] measured the strain of a PHC pipe pile during static load testing based on the FBG strain sensors and strain gauges. Weng et al. [30] installed FBG strain sensors on the surface of the pile using an epoxy resin to monitor the strain state of the model pile during centrifugal testing. Baldwin et al. [31] installed FBG sensors in the shallow grooves of a pile and protected the sensors using an epoxy resin. Schilder et al. [32] measured the strain in concrete piles under static and dynamic loads based on FBG strain sensors to evaluate the bearing capacity. Liu et al. [33] monitored the end and shaft resistances of an open-ended PHC pipe pile using FBG strain sensors. Doherty et al. [34] adopted FBG sensors to measure the strain of precast piles and steel pipe piles and found that these sensors can well meet the testing requirements for different pile foundations. The central wavelength of FBG sensors is influenced by the temperature and strain [35-37]. However, the influence of temperature changes on the accuracy of the FBG strain sensor is often ignored in the existing studies. To improve the monitoring accuracy of FBG strain sensors in pile tests, the temperature should be compensated for, especially in cold regions.

To investigate the capacity properties of closed PHC pipe piles during penetration into a layered stratum, a full-scale test was conduct based on an actual project located in Shandong province, China. The low-temperature sensitive, FBG strain sensors, and FBG temperature sensors were installed in the shallow grooves along opposite sides of the PHC pipe piles. Thus, the strain of the PHC pipe piles can be measured to avoid the effects of temperature under hydraulic driving. Thus, the axial force, end resistance, shaft resistance, and unit shaft resistance of the $\mathrm{PHC}$ pipe pile under hydraulic driving can be calculated. The research results can provide reference and guidance for jacked pile engineering in a cold region.

\section{Site Conditions and Test Program}

2.1. Site Conditions. The test site is situated in Dongying City, Shandong Province, China, in the quaternary alluvial plain landform of the Yellow River Delta. The surface layer is backfill soil with a thickness of $0.9-5.3 \mathrm{~m}$, and the buried depth of the groundwater level is $0.30-3.00 \mathrm{~m}$. The soil parameters of the test site are as shown in Table 1.

\subsection{Installation of PHC Pipe Piles with FBG Sensors for Field} Monitoring. In the tests, the PHC-A400 (95) prestressed high-strength concrete pipe pile was used for testing. The pile length was $12 \mathrm{~m}$, Young' modulus was $36 \mathrm{GPa}$, axial compressive strength was $35.9 \mathrm{MPa}$, and the tested piles are denoted as P1 and P2. Before installing the sensors, a mark was placed on the pile body, and a slotting machine was used to make a shallow groove at a depth of $2 \mathrm{~cm}$ and a width of $4 \mathrm{~cm}$. After slotting, the sensor position was leveled to avoid eccentrically compressing the sensors during pile pressing. The support of the sensor was fixed in the shallow groove using epoxy resin, and the FBG sensor was installed after the epoxy resin hardened. After the sensors were installed, the shallow groove was filled with epoxy resin and made flush with the surface of the pile body. The cable of the FBG sensor was led out from the drilled hole on the top of the pile. The procedures for the installation are shown in Figure 1.

In the test, six FBG strain sensors and FBG temperature sensors were installed in one side along the pile, and another seven FBG sensors were at the opposite side. The installation positions of the FBG sensors are as shown in Figure 2. The performance parameters of FBG sensors are as shown in Table 2. The distance of center of the sensor closest to the pile end was $20 \mathrm{~cm}$ from the pile end to avoid the influence of the pile end plate on the measurement.

The test used a 680-ton hydraulic pile driver with a maximum stroke of $1.8 \mathrm{~m}$. It was difficult to control the penetration rate at a fixed value as the penetration depth increased during the process. The pile penetration speed was approximately $1.8-3 \mathrm{~m} / \mathrm{min}$. At the initial stage of pile penetration, the lower penetration resistance caused the pile penetration speed to be slightly larger. As the penetration depth increased, the resistance to penetration gradually increased and reduced the pressing speed. Bond et al. [38] defined a penetration rate of more than $0.4-0.6 \mathrm{~m} / \mathrm{min}$ as a fast penetration and a penetration rate of $0.005-0.10 \mathrm{~m} / \mathrm{min}$ as a slow penetration. In this test, the pile jacking process is considered as fast penetration. In the penetration process, the pile length was used as the final pressure control standard. The test data were collected using the FS 2200RMRack-Mountable Bragg Meter demodulator produced by Portugal, which directly collected the wavelength difference from the center wavelength of the fiber grating.

\section{Test Results and Discussion}

3.1. Variation of Jacking Force with Penetration Depth. As shown in Figure 3, the jacking forces increased with the penetration depth. The jacking forces of P1 and P2 show similar characteristics with the penetration depths from 0-5.0 $\mathrm{m}$. The jacking forces of P1 and P2 increased by factors of approximately 2.8 and 2.2 with the penetration depth from $5.0-7.8 \mathrm{~m}$ and $7.9 \mathrm{~m}$, respectively, because the resistance of silty soil was greater and the jacking force must be increased to further press the pile into the soil. When the pile end penetrated the silty clay layer, the jacking force decreased: P1 decreased from 1160 to $778 \mathrm{kN}$, and P2 decreased from 855 to $564 \mathrm{kN}$. The penetration resistance is mainly determined by the average strength of the soil layer within $2.5 \mathrm{D}$ below the pile end, which is the main reason for differences in the jacking forces between P1 and P2. This indicates that the jacking force is affected primarily by the type of soil layer at the end of the pile.

3.2. Variation of Axial Force with Penetration Depth at Six Penetration Depths. Through the wavelength difference of sensors measured, the axial strain $\varepsilon$ of the pile can be calculated by

$$
\frac{\Delta \lambda}{\lambda}=S_{\varepsilon} \cdot \varepsilon=\left(1-P_{e}\right) \cdot \varepsilon
$$


TABLE 1: Soil parameter.

\begin{tabular}{|c|c|c|c|c|c|c|c|c|}
\hline $\begin{array}{l}\text { Soil } \\
\text { type }\end{array}$ & Soil description & $\begin{array}{l}\text { Thickness } \\
\text { (m) }\end{array}$ & $\begin{array}{c}\text { Water } \\
\text { content, } \omega \\
(\%)\end{array}$ & $\begin{array}{l}\text { Unit weight, } \\
\gamma\left(\mathrm{kN} / \mathrm{m}^{3}\right)\end{array}$ & $\begin{array}{l}\text { Void } \\
\text { ratio, } e_{0}\end{array}$ & $\begin{array}{c}\text { Cohesion, } c \\
(\mathrm{kPa})\end{array}$ & $\begin{array}{c}\text { Internal } \\
\text { friction angle, } \phi \\
\left({ }^{\circ}\right)\end{array}$ & $\begin{array}{c}\text { Compression } \\
\text { modulus, } E_{\mathrm{s}}(\mathrm{MPa})\end{array}$ \\
\hline Fill & Plastic clay & $0.9-5.3$ & 30.6 & 18.5 & 0.867 & 13.8 & 6.8 & 4.1 \\
\hline $\begin{array}{l}\text { Silty } \\
\text { soil A1 }\end{array}$ & $\begin{array}{l}\text { Loose dense silty } \\
\text { soil }\end{array}$ & $0.3-2.5$ & 28.8 & 18.6 & 0.803 & 8.7 & 20.1 & 8.1 \\
\hline $\begin{array}{l}\text { Silty } \\
\text { clay B1 }\end{array}$ & Soft plastic clay & $0.3-1.9$ & 30.9 & 18.3 & 0.876 & 17.6 & 7.4 & 4.8 \\
\hline $\begin{array}{l}\text { Silty } \\
\text { soil A2 }\end{array}$ & $\begin{array}{l}\text { Medium dense } \\
\text { silty soil }\end{array}$ & $0.3-4.0$ & 28.3 & 18.7 & 0.794 & 8.7 & 21 & 8.7 \\
\hline $\begin{array}{l}\text { Silty } \\
\text { clay B2 }\end{array}$ & $\begin{array}{l}\text { Soft plastic to flow } \\
\text { plastic clay }\end{array}$ & $2.6-4.6$ & 31.7 & 18.3 & 0.895 & 17.5 & 6.8 & 4.6 \\
\hline $\begin{array}{l}\text { Silty } \\
\text { soil A3 }\end{array}$ & $\begin{array}{l}\text { Medium dense } \\
\text { silty soil }\end{array}$ & $0.8-3.8$ & 28.3 & 18.7 & 0.793 & 10.3 & 20.6 & 10.2 \\
\hline
\end{tabular}

Note. $c$ and $\phi$ were determined using the quick shear tests, and $E_{\mathrm{s}}$ was determined using the one-dimensional compressibility test; the thickness was obtained by the auger boring test.

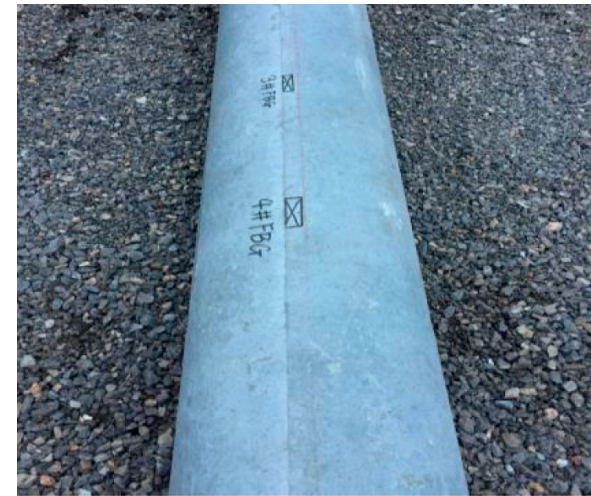

(a)

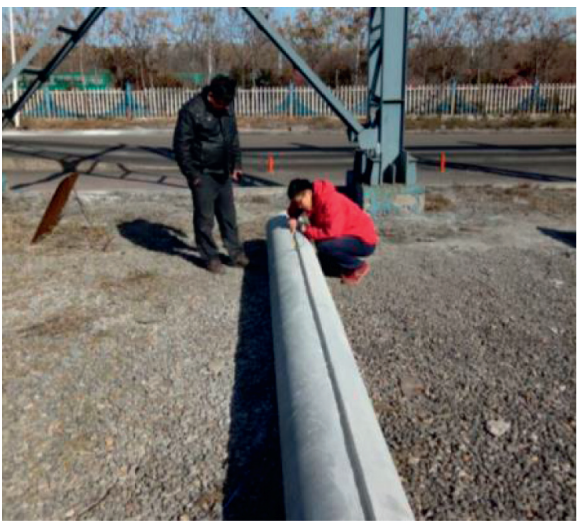

(c)

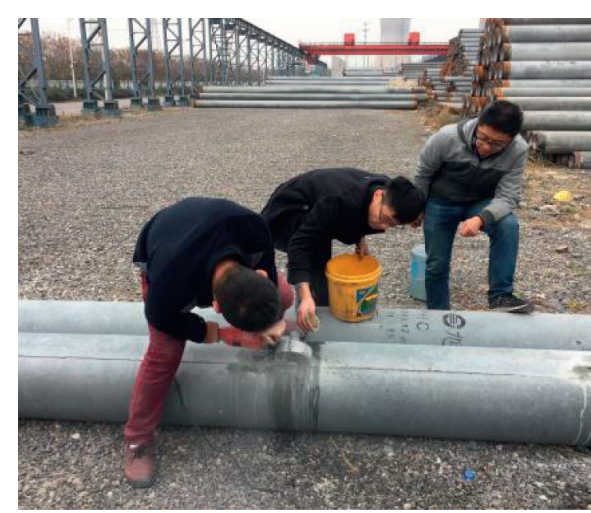

(b)

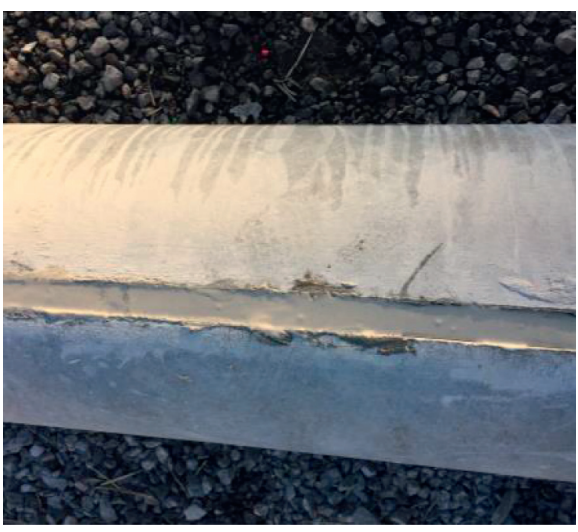

(d)

FIGURE 1: FBG sensor installation process: (a) marking the sensor locations; (b) slotting with a machining tool, (c) installing the sensor, and (d) sealing with epoxy resin.

where $\Delta \lambda_{\mathrm{B}}$ is the wavelength difference; $\lambda_{\mathrm{B}}$ is the center wavelength of the reflected light; $S_{\varepsilon}$ is the strain sensitivity coefficients with $S=1-P_{e}=0.784 / \mu \varepsilon ; P_{e}$ is the valid elastic-optic constant; and $\varepsilon$ is the axial strain of the pile.

In the test, FBG strain sensors were installed on both sides of the pile, and the axial strain of the pile at level $i$ can be calculated by

$$
\varepsilon_{\mathrm{Ni}}=\frac{\varepsilon_{\mathrm{FBGi}}+\varepsilon_{\mathrm{FBGi}}{ }^{\prime}}{2}
$$

where $\varepsilon_{\mathrm{Ni}}$ is the average axial strain of the pile at level $i(i=1$, $\ldots, 6)$ and $\varepsilon_{\mathrm{FBG} i}$ and $\varepsilon_{\mathrm{FBG} i}$ are the axial strains measured by two FBG strain sensors installed at the same depth.

The axial force $F_{i}(i=1, \ldots, 6)$ of the pile at section $i$ can be calculated by 


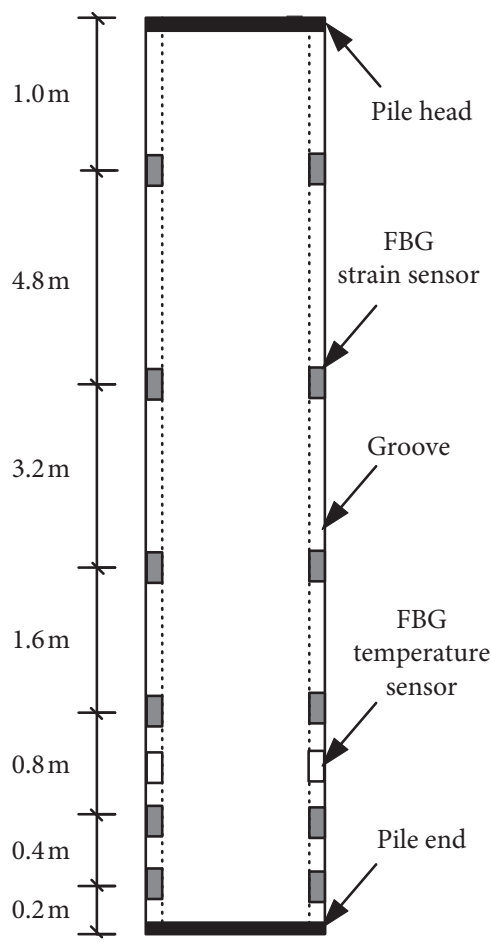

Figure 2: Installation position of the FBG sensors.

TABLE 2: The performance parameters of FBG sensors.

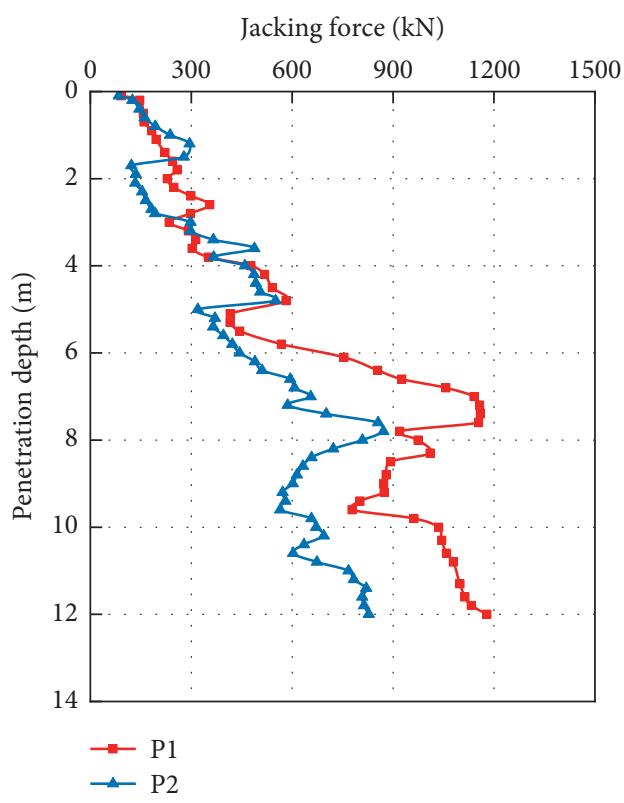

FIGURE 3: Jacking force versus penetration depth. 


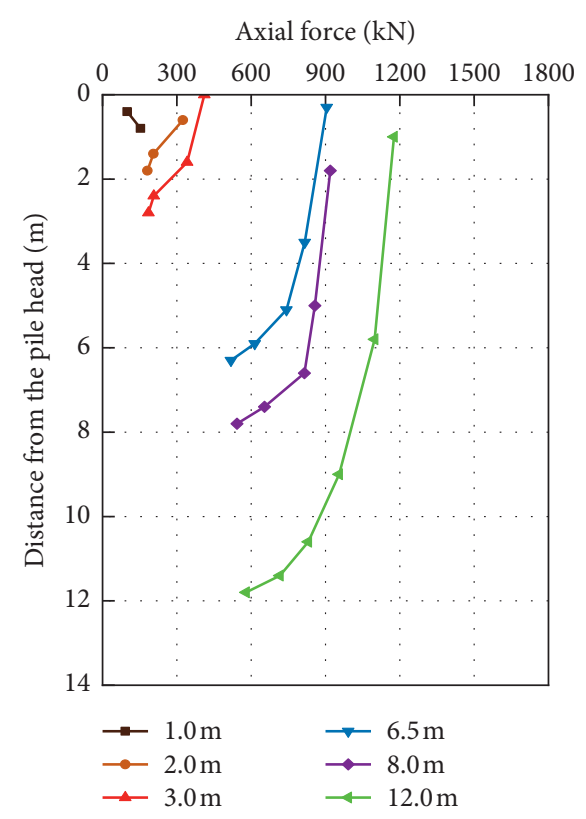

(a)

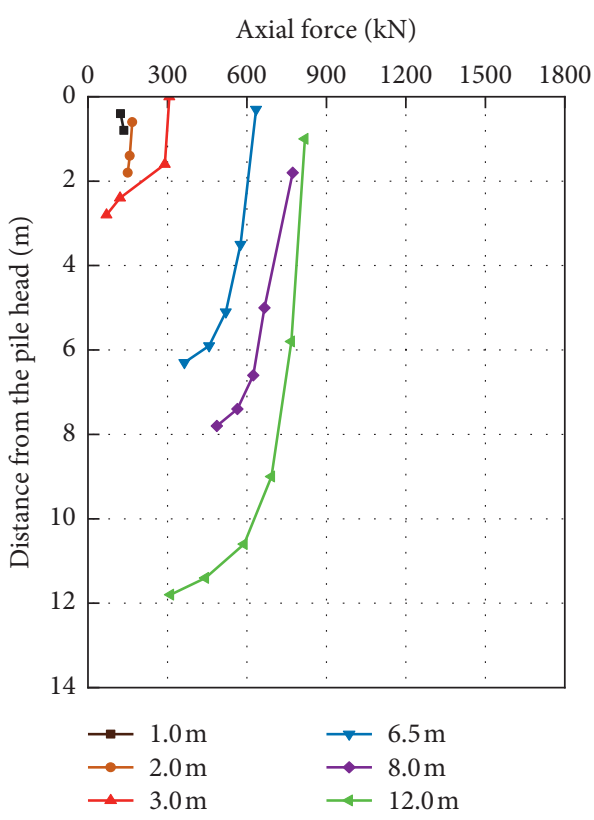

(b)

FIgURE 4: Axial force profiles along the piles at different penetration depths: axial forces of (a) P1 and (b) P2.

$$
F_{i}=A_{p} E_{p} \varepsilon_{\mathrm{Ni}}
$$

where $A_{p}$ is the cross-sectional area of the pile and $E_{p}$ is Young's modulus.

As shown in Figure 4, the axial forces of P1 and P2 at 1.0, 2.0, 3.0, 6.5, 8.0, and $16.0 \mathrm{~m}$ penetration depths are calculated using equation (3). The axial forces of $\mathrm{P} 1$ and $\mathrm{P} 2$ at a given soil depth increase with the penetration depth from $1.0-2.0 \mathrm{~m}$ until $12.0 \mathrm{~m}$. The trend of the axial force in Figure 4(a) for P1 is similar to that of Figure 4(b) for P2 except for a few differences in the values. The axial forces along the piles decrease with the distance from the pile head at a given penetration depth. This indicates that the axial forces are related to both the penetration depth and the shaft resistance.

\subsection{Variation of End and Shaft Resistances with Penetration} Depth. As shown in Figure 5, the end resistances of P1 and P2 increased with the penetration depth. The end resistances were obtained from the value of the sensor near the bottom of pile. The trends in Figure 5 for P1 are similar to those for $\mathrm{P} 2$ with some differences. When the pile end penetrated the silty soil layer, the end resistance increased: P1 increased from 365 to $735 \mathrm{kN}$ and P2 increased from 234 to $490 \mathrm{kN}$. In order to reduce the influence between $\mathrm{P} 1$ and $\mathrm{P} 2$ piles, the pile distance is set to $2.0 \mathrm{~m}$, which is the reason for the large difference between $\mathrm{P} 1$ and $\mathrm{P} 2$ piles. This can be explained as the end resistances being affected by the soil layer at the different pile positions.

As shown in Figure 6, when the penetration depth was 0-3.0 m, the shaft resistances for P1 and P2 increased slowly. This is because pile sloshing and shallow soil uplift cause the pile-soil interface contact to be loose with a small radial

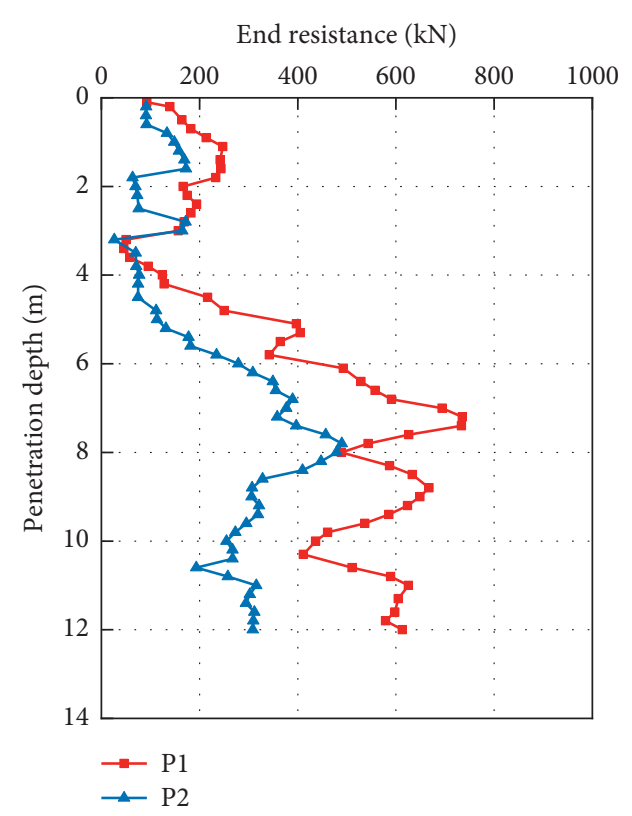

Figure 5: End resistance versus penetration depth.

effective stress. When the penetration depth was around $4 \mathrm{~m}$ (when the pile end entered the silty clay layer from the silt layer), the shaft resistance initially decreased and then increased. This is because the end of the pile entered the clay layer, which suddenly decreased the end resistance of the pile. The pressing speed of the pile increased sharply, and there was a thick mud film between the pile and the soil, which reduced the shaft resistance of the pile. The decreased end resistance of the pile caused an increased tangential force of the pile body and increased the adhesion force between the pile and the soil. 


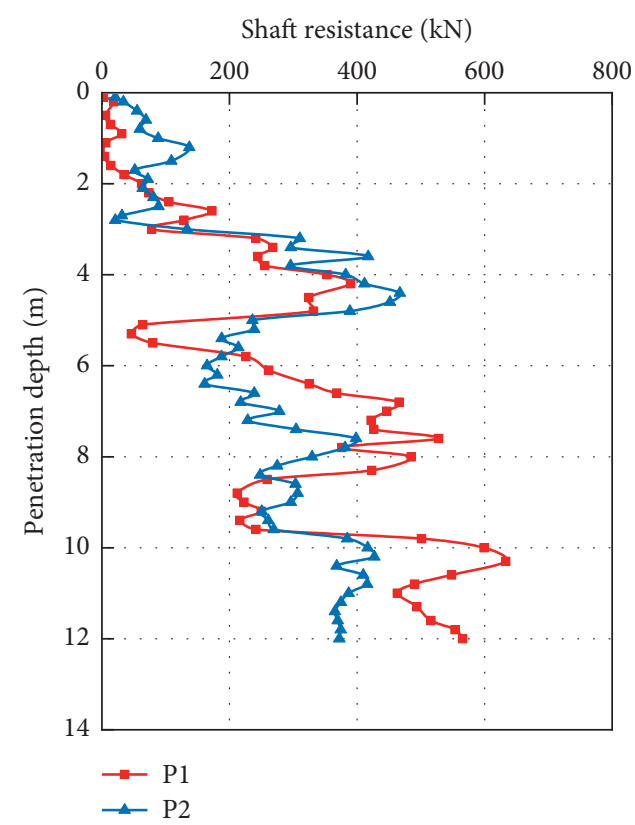

Figure 6: Shaft resistance versus penetration depth.

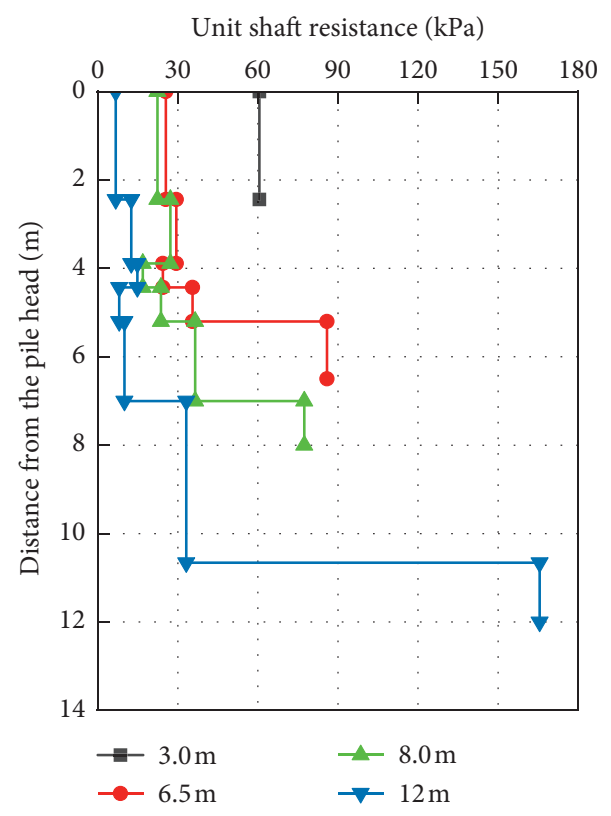

(a)

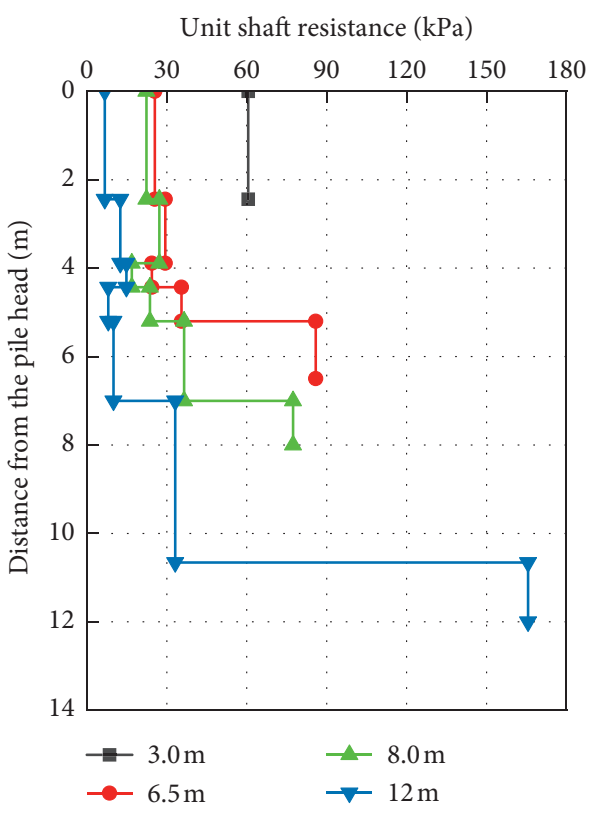

(b)

FIGURE 7: Unit shaft resistance along piles at different penetration depths: unit shaft resistances of (a) P1 and (b) P2.

3.4. Variation of Unit Shaft Resistance with Penetration Depth. The unit shaft resistance of the pile can be calculated as

$$
f=\frac{\left(F_{i}-F_{i-1}\right)}{\left[\pi D_{0}\left(h_{i}-h_{i-1}\right)\right]}
$$

where $F_{i}$ is the axial force at level $i, F_{i-1}$ is the axial forces at level $i-1, h_{i}-h_{i-1}$ is the distance between levels $i$ and $i-1$, and $D_{0}$ is the external diameter of the pile.

As shown in Figures 7(a) and 7(b), the unit shaft resistances of $\mathrm{P} 1$ and $\mathrm{P} 2$ at penetration depths of 3.0, 6.5, 8.0, and $12.0 \mathrm{~m}$ can be calculated from equation (4). The unit shaft resistances of the piles at a given penetration depth does not increase gradually with the distance from the pile head. The trends of the unit shaft resistances for P1 and P2 in Figures 7(a) and 7(b) are distinct, but with some similarities. This indicates that the unit shaft resistances are related to the distribution and parameters of the soil layers. The unit shaft resistance at a given soil depth decreased with the penetration depth from $3.0-6.5 \mathrm{~m}$ until $12.0 \mathrm{~m}$. This can be explained as the side soil of the pile at a given soil depth was 
continuously sheared and squeezed by the pile, which disturbed the soil and decreased the shear strength.

\section{Summary and Findings}

This paper monitored the strain and temperature state of PHC pipe piles during jacking using low-temperature sensitive, FBG, strain sensors, and FBG temperature sensors. The following conclusions are drawn.

(1) The low-temperature sensitive, FBG strain sensors, and FBG temperature sensors were installed on the surface of PHC pipe pile using the slot-embedding method. The installation method of the sensors improved their survival rate. The low-temperature sensitive, FBG, and strain sensors used in this study can better satisfy the monitoring requirements of PHC pipe pile penetration characteristics during jacking than traditional approaches.

(2) The distribution of the soil layers affects the jacking force and end resistance, and the change laws of the jacking force and end resistance with depth reflect the soil layer distributions. When the pile end penetrated the silty clay layer, the jacking force and end resistance increased by factors of 2.5 and 2, respectively.

(3) At a given depth, as the penetration depth of the PHC pipe pile increased, the pile and soil continuously sheared each other and the radial stress on the side of the pile gradually released. This resulted in a decreased unit shaft resistance. The shaft resistance gradually deteriorated, which caused the unit shaft resistance of the piles to gradually decrease and show a significant degradation.

\section{Data Availability}

The Microsoft Excel Worksheet data used to support the findings of this study are available from the corresponding author (wangyonghong@edu.qut.cn) upon request.

\section{Conflicts of Interest}

The authors declare that they have no conflicts of interest.

\section{Acknowledgments}

This research was supported financially by the National Natural Science Foundation of China (51708316, 51778312, and 51809146) and the Shandong Province Emphasis Research Program, China (2017GSF16107, 2018GSF117010, and 2018GSF117008).

\section{References}

[1] H. L. Kou, J. Chu, W. Guo, and M. Y. Zhang, "Field study of residual forces developed in pre-stressed high-strength concrete (PHC) pipe piles," Canadian Geotechnical Journal, vol. 53, no. 4, pp. 696-707, 2016.
[2] J. Kim and G. Yea, "Case study of comparative analysis between static and dynamic loading test of PHC pile," Journal of the Korean Geoenvironmental Society, vol. 14, pp. 13-23, 2013.

[3] J. T. Wu, X. Ye, J. Li, and G. W. Li, "Field and numerical studies on the performance of high embankment built on soft soil reinforced with PHC piles," Computers and Geotechnics, vol. 107, pp. 1-13, 2019.

[4] H.-F. Xing, H.-W. Zhao, G.-B. Ye, and C. Xu, "Effect of driving long pre-stressed high-strength concrete pipe piles in alluvium and its mechanical behavior," Bulletin of Engineering Geology and the Environment, vol. 71, no. 4, pp. 771-781, 2012.

[5] L. Li, W. Wu, M. Hesham El Naggar, G. Mei, and R. Liang, "DEM analysis of the sand plug behavior during the installation process of open-ended pile," Computers and Geotechnics, vol. 109, pp. 23-33, 2019.

[6] H.-L. Kou, W. Guo, and M.-Y. Zhang, "Field study of set-up effect in open-ended PHC pipe piles," Marine Georesources \& Geotechnology, vol. 35, no. 2, pp. 208-215, 2017.

[7] F.-y. Huang, S.-w. Wu, X.-y. Luo, B.-c. Chen, and Y. Lin, "Pseudo-static low cycle test on the mechanical behavior of PHC pipe piles with consideration of soil-pile interaction," Engineering Structures, vol. 171, pp. 992-1006, 2018.

[8] J. Zhang, Q.-q. Zhang, R.-f. Feng, S.-w. Liu, and S.-m. Zhang, "Discussion of Field study of residual forces developed in prestressed high-strength concrete (PHC) pipe piles," Canadian Geotechnical Journal, vol. 54, no. 4, pp. 600-601, 2017.

[9] G. W. Li, H. F. Pei, J. H. Yin, X. C. Lu, and J. Teng, "Monitoring and analysis of PHC pipe piles under hydraulic jacking using FBG sensing technology," Measurement, vol. 49, pp. 358-367, 2014.

[10] H. L. Kou, W. Z. Diao, T. Liu, D. L. Yang, and S. Horpibulsuk, "Field Performance of open-ended prestressed high-strength concrete pipe piles jacked into clay," Sensors, vol. 18, no. 12, p. 4216, 2018.

[11] X. Wang, "Field test investigation of the pile jacking performance for prefabricated square rigid-drainage piles in saturated silt sandy soils," Advances in Civil Engineering, vol. 2019, Article ID 4587929, 11 pages, 2019.

[12] P. A. Cyril, S. T. Kok, M. K. Song, A. Chan, J.-Y. Wong, and W. K. Choong, "Smooth particle hydrodynamics for the analysis of stresses in soil around Jack-in Pile," European Journal of Environmental and Civil Engineering, vol. 2019, pp. 1-27, 2019.

[13] Y. Wang, B. Shi, T. Zhang, H. Zhu, Q. Jie, and Q. Sun, "Introduction to an FBG-based inclinometer and its application to landslide monitoring," Journal of Civil Structural Health Monitoring, vol. 5, pp. 1-9, 2015.

[14] Y. J. Rao, "Recent progress in applications of in-fibre Bragg grating sensors," Optics and Lasers in Engineering, vol. 31, no. 4, pp. 297-324, 1999.

[15] C. Y. Hong, J. H. Yin, W. Jin, C. Wang, W. H. Zhou, and H. H. Zhu, "Comparative study on the elongation measurement of a soil nail using optical lower coherence interferometry method and FBG method," Advances in Structural Engineering, vol. 13, pp. 309-319, 2010.

[16] H. I. Kim, J. S. Yoon, H. B. Kim, and J. H. Han, "Measurement of the thermal expansion of space structures using fiber Bragg grating sensors and displacement measuring interferometers," Measurement Science and Technology, vol. 21, Article ID 085704, 2010.

[17] J. Zhou, Y. Zhang, M. Mulle, and G. Lubineau, “Temperature sensing of micron scale polymer fibers using fiber Bragg gratings," Measurement Science and Technology, vol. 26, Article ID 085003, 2015. 
[18] B. Degamber and G. F. Fernando, "Process monitoring of a thermosetting resin using optical-fiber sensors in a microwave environment," IEEE Sensors Journal, vol. 4, no. 6, pp. 713-721, 2004.

[19] H. H. Zhu, J. H. Yin, A. T. Yeung, and W. Jin, "Field pullout testing and performance evaluation of GFRP soil nails," Journal of Geotechnical and Geoenvironmental Engineering, vol. 137, pp. 633-642, 2010.

[20] M. R. A. Hassan, M. H. A. Bakar, K. Dambul, and F. R. M. Adikan, "Optical-based sensors for monitoring corrosion of reinforcement rebar via an etched cladding Bragg grating," Sensors, vol. 12, no. 11, pp. 15820-15826, 2012.

[21] A. Barrias, J. R. Casas, and S. Villalba, "A review of distributed optical fiber sensors for civil engineering applications," Sensors, vol. 16, no. 5, p. 748, 2016.

[22] H.-H. Zhu, B. Shi, and C.-C. Zhang, "FBG-based monitoring of geohazards: current status and trends," Sensors, vol. 17, no. 3 , p. 452, 2017.

[23] D. Obermayer and C. O. Kappe, "On the importance of simultaneous infrared/fiber-optic temperature monitoring in the microwave-assisted synthesis of ionic liquids," Organic and Biomolecular Chemistry, vol. 8, no. 1, pp. 114-121, 2010.

[24] D. Wada and H. Murayama, "Analytical investigation of response of birefringent fiber Bragg grating sensors in distributed monitoring system based on optical frequency domain reflectometry," Optics and Lasers in Engineering, vol. 52, pp. 99-105, 2014.

[25] A. Klar, P. J. Bennett, K. Soga et al., "Distributed strain measurement for pile foundations," Proceedings of the Institution of Civil Engineers-Geotechnical Engineering, vol. 159, no. 3, pp. 135-144, 2006.

[26] Y. Lu, B. Shi, G. Q. Wei, S. E. Chen, and D. Zhang, “Application of a distributed optical fiber sensing technique in monitoring the stress of precast piles," Smart Materials and Structures, vol. 21, no. 11, Article ID 115011, 2012.

[27] Y. Ding, P. Wang, and S. Yu, "A new method for deformation monitoring on H-pile in SMW based on BOTDA," Measurement, vol. 70, pp. 156-168, 2015.

[28] Z. S. Guo and Z. Y. Zhao, "Application of distributed optical fiber sensing technique in pile foundation monitoring," IOP Conference Series: Earth and Environmental Science, vol. 189, Article ID 052074, 2018.

[29] W. Lee, W.-J. Lee, S.-B. Lee, and R. Salgado, "Measurement of pile load transfer using the Fiber Bragg Grating sensor system," Canadian Geotechnical Journal, vol. 41, no. 6, pp. 1222-1232, 2004.

[30] X. L. Weng, J. X. Chen, and J. Wang, "Fiber Bragg gratingbased performance monitoring of piles fiber in a geotechnical centrifugal model test," Advances in Materials Science and Engineering, vol. 2014, Article ID 659276, 8 pages, 2014.

[31] C. S. Baldwin, T. Poloso, P. C. Chen, J. B. Niemczuk, J. S. Kiddy, and C. Ealy, "Structural monitoring of composite marine piles using fiber optic sensors," in SPIE's 8th Annual International Symposium on Smart Structures and Materials, vol. 4330, pp. 487-497, International Society for Optics and Photonics, Bellingham, WA, USA, 2001.

[32] C. Schilder, H. Kohlhoff, D. Hofmann et al., "Static and dynamic pile testing of reinforced concrete piles with structure integrated fibre optic strain sensors," in Proceedings of the Fifth European Workshop on Optical Fibre Sensors, Krakow, Poland, May 2013.

[33] J. W. Liu, Z. M. Zhang, F. Yu, and Z. Z. Xie, "Case history of installing instrumented jacked open-ended piles," Journal of
Geotechnical and Geoenvironmental Engineering, vol. 138, no. 7, pp. 810-820, 2011.

[34] P. Doherty, D. Igoe, G. Murphy et al., "Field validation of fibre Bragg grating sensors for measuring strain on driven steel piles," Géotechnique Letters, vol. 5, no. 2, pp. 74-79, 2015.

[35] G. Meltz, W. W. Morey, and W. H. Glenn, "Formation of Bragg gratings in optical fibers by a transverse holographic method," Optics Letters, vol. 14, no. 15, pp. 823-825, 1989.

[36] D. Z. Anderson, V. Mizrahi, T. Erdogan, and A. E. White, "Production of in-fibre gratings using a diffractive optical element," Electronics Letters, vol. 29, no. 6, pp. 566-568, 1993.

[37] V. Richter-Trummer, S. O. Silva, D. F. C. Peixoto et al., "Fibre Bragg grating sensors for monitoring the metal inert gas and friction stir welding processes," Measurement Science and Technology, vol. 21, Article ID 085105, 2010.

[38] A. J. Bond and R. J. Jardine, "Shaft capacity of displacement piles in high OCR clay," Geotechnique, vol. 45, no. 1, pp. 3-23, 1995. 